\title{
Transforming learning for the smart learning environment: lessons learned from the Intel education initiatives
}

\author{
Jon K. Price
}

\section{Correspondence:}

Jon.k.price@intel.com

Research Scientist, Intel Education,

Intel Corporation, 1600 Rio Rancho

Blvd. S.E. RR5-331, Rio Rancho, NM

87124, USA

\section{Springer}

\begin{abstract}
This paper examines contextual factors of effective ICT implementation for smart learning environments resulting from a review of exploratory research, evaluation data and study reports of successful ICT use in schools around the world. By referencing the design and implementation components of the Intel ${ }^{\circledR}$ education initiatives for education transformation, this paper will illustrate the key intervention considerations and challenges associated with technology integration, policy recommendations, and sustainable resources. Transforming education systems and supporting national competitiveness are challenging, long-term endeavors and require a holistic multidimensional approach. On-going support, embedded monitoring and visionary leadership can inform policies, teaching and learning processes and professional development to enable reform efforts that support real change.
\end{abstract}

Keywords: Classroom, Reform, ICT, Smart learning

\section{Introduction}

While technology has changed what is possible to learn and how students can be supported in their learning, the principles of effective instruction haven't changed. The technology does not drive learning, it is simply what mediates and supports the process. It is vital that professors, instructors and teachers remain focused on the effective process of learning and their own teaching strategies and methods. The technology changes how effective teaching strategies can be achieved more accessible and at a higher level (Means et al. 2009).

Increasingly around the world, there is recognition of the opportunity for information and communication technologies (ICT) in education. However, specific use models of technology in education remain broad and ill-defined. Inevitably, conversations turn to questions regarding the effectiveness of technology integration and what impact technology plays in the quality of teaching and learning in today's classroom. In response to the uncertainty regarding opportunities and challenges facing education systems in transforming the classroom into effective teaching and learning environments, Intel Corporation has explored innovative uses of technology that presents new ways to explore, learn, and share knowledge in technology enabled smart learning environments.

For those in the private sector who are involved in the many aspects of education and technology, the questions asked frequently challenge both the motives for their involvement, the efforts associated with understanding the effectiveness of these efforts,

(C) 2015 Price. Open Access This article is distributed under the terms of the Creative Commons Attribution 4.0 International License (http://creativecommons.org/licenses/by/4.0/), which permits unrestricted use, distribution, and reproduction in any medium, provided you give appropriate credit to the original author(s) and the source, provide a link to the Creative Commons license, and indicate if changes were made. 
and the long term commitment to guarantee sustainability. There is rarely agreement on the roles and methods of such private sector involvement, but there is agreement that, as the demand for high-level subject based skills and higher order 21st Century skills continue to grow within schools and beyond for future employability, the tasks associated with transforming traditional models of schooling to meet these demands are often hidden within the complex political, social, and educational systems in which they are so deeply embedded. Increasingly, the private sector is establishing partnerships with governments, non-governmental organizations, academia, educators, practitioners and industry to address the challenges associated with the numerous education reform efforts. For multinational corporations, their global presence and needs as employers provides a perspective that can inform agencies intent upon transforming learning environments and learning outcomes in local and global ways. Identification of the activities that support a shift from traditional education systems to the desired innovative and personalized learning environment will require exploration beyond the classroom to include the wide-ranging systemic change of programs, practices, and policies based on the application of a clear theory of change.

For more than four decades, Intel has made education the primary focus of its strategic philanthropic activities. Investing more than $\$ 100$ million annually in programs that promote teacher professional development, STEM education, foster and celebrate innovation and entrepreneurship among the best and brightest young students in the world, and supporting initiatives that encourage women and girls to seek careers in technology, each helping incorporate best practices in math, science and the effective use of technology in formal and informal education environments.

Working in coalitions with other high-tech companies to support technology access, development and implementation of K-12 teacher professional development has helped provide valuable insight into effective integration of technology. Working on projects to improve mathematics and science content and curriculum, as well as assessments to support initiatives that develop 21st century skills, utilizing technology helped provide better understanding in ways to enable the skills students need to be the innovators of tomorrow. To address this need for technology to be integrated in ways that move beyond hardware access and software applications, Intel supports programs and initiatives designed to train classroom teachers to integrate technology into their lessons to promote problem solving, critical thinking and collaboration skills among their students into their existing curriculum. To date, the Intel teacher professional development efforts, have trained over ten million teachers in more than 70 countries worldwide. Most recently, Intel has implemented a solutions approach to support education systems. This approach integrates device technology developments with locally relevant solutions, hardware, software and tools for learning to create a more vibrant, interactive learning environment.

In addition to program and infrastructure investments, Intel has also invested in exploratory research and rigorous program evaluation to establish and sustain continuous improvement of these educational products and activities. The research and evaluation compiled for this purpose has not only enabled the improvements of the program development efforts, but now also comprises a comprehensive body of evidence that demonstrates program impact (Price et al. 2011a). As a result of these efforts, critical evidence has emerged that may inform other evaluation activities designed to measure impact related to ICT in education in terms that extend beyond logistical deployment and high stakes testing. 
It is the result of the global initiatives, governmental, NGO \& private sector partnerships and data collected across the globe has resulted in the development of a strategic education transformation model. Developed through the Intel education initiatives, and sustained through a number of ongoing initiatives, the model has been found to help address concerns in designing strategies involving large scale education transformation initiatives.

\section{Considerations for creating smart learning environments}

Intel began its education initiatives in the early 1990's during the introduction of computers in US classrooms. At that time, the Intel Foundation examined the few teacher professional development programs available to help teachers use this new technology in their efforts to improve student learning, (West 1990; Yost J, McMillan-Culp K, Bullock D, Kuni, P. Intel Teach to the Future: A Worldwide Teacher Professional Development Program Combining Inquiry-Based Education with Technology Integration. Tracks to the Future: Integrating Technology into Today's Schools. Unpublished NM Association for Supervision and Curriculum Development.). The critical concern at the time was if teachers understood how technology could be used to support classroom instruction. Earliest professional development programs focused on hardware and software use, but soon shifted to emphasize the instructional purpose of the technology and the impact on education (Makrakis 1991), as well as the need for an improved quality and nature of teacher-training (Hannifan, et al. 1987).

Today, as education systems are currently undergoing significant change brought about by emerging reform in pedagogy and technology, Intel's efforts have sought to close the gap between technology as an educational additive to effective integration as a means to promote and cultivate student centered, inquiry based and project based learning. Moving forward, many of the advances in education will be brought about by further integration of personalized learning into the smart learning environment, such as ubiquitous access to technology through continuously shifting mobile devices and mobile platforms, cloudbased services, big data, and dispersed learning environments will further emphasize the affordances of learning technologies. These changes are also being impacted by broader trends including population shifts, economics, employment, and other societal shifts.

In her research on improving instruction, Karen Douglas noted that, "Classroom instruction is a complex enterprise that occurs at the intersection of teachers, students, and texts within the surrounding classroom, school, and community environments." (Douglas 2009, p. 518) Effective education reform and sustained policy-based (macro) initiatives to enhance equity and excellence must be designed and understood at the school (meso) level and implemented at the classroom (micro) level, (Scheuermann et al. 2009) (Price and Roth 2010). With the addition of smart learning environments to these educational contexts, the complexity increases as reforms to teaching and learning strategies now include innovative uses, emerging pedagogical approaches and technologies designed for, and implemented at, the individual student level.

In the wake of technology integration for instruction efforts, there is no shortage in the number of claims that describe the many disappointments of ICT in education. At worst, these illustrate reform failures or worst practices, (Trucano 2010). and at best, many results simply provide no significant difference in attaining student performance improvements (Barrera-Osorio and Linden 2009). However, a closer look into these studies, often shines light on poorly aligned success criteria and measurements. In order to transform general project goals and objectives into observable and measurable 
phenomena, it is crucial to have a clear and realistic understanding of the project design and reasonable expectations. The evaluation design must consider that schools are full of complex political and social dynamics. For example, it is difficult to expect a project designed for innovative inquiry based learning strategies to improve student test scores, if the tests remain traditional, multiple choice instruments that do not reflect the inquiry based strategies. Similarly, it is equally challenging for project based instruction strategies to be sustained if curriculum and assessment requirements are not reformed as well.

If we were to revisit the idea that meaningful measures of student knowledge must be understood through the lens of multiple intersecting forces, and if we acknowledge that a change in the assessment process itself can result in a learning experience and deepen student engagement, then we must also acknowledge a need for a change in multiple education practices and relationships to understand new instructional practice and learner outcomes. The interplay between these complex educational components is the basis behind the Intel education transformation model, and its role in smart learning environments.

\section{Intel education transformation model}

As a result of the research and evaluation efforts that have supported the Intel education programs, it became clear that there was a need for a comprehensive approach to systemic education reform. In the early stages of the global deployment of the teacher professional development program known at the time as Intel Teach to the Future, impact evaluations were conducted to understand the extent the instructional strategies were implemented in participant teacher's classrooms. Four key indicators were developed based on this global impact data:

- Increased use of technology for lesson planning and preparation

- Implementation of all or part of the unit plan designed in the training

- Use of technology in new ways with students

- Increase in project based learning activities with students (Light and Pierson 2011).

While approaching the ten year anniversary of the program, a global review was conducted. Survey responses across participating countries indicated that $93.9 \%$ of the teachers who took what had become the Intel ${ }^{\bullet}$ Teach Essentials course reported changing the way they teach in at least one of the program success indicators (Price et al. 2011a).

However, not all participating countries achieved these same results. When the evaluation data was investigated within the implementation of the program at sites failing to achieve these results, it was the systemic factors that prevented effective implementation. For example, relevant teacher professional development is meaningless if release time for teachers prevents them from participating in the first place. In addition, increased technology use or project based learning activities are meaningless if sufficient content and assessments aren't available to apply these new skills. As a result, Intel's Education Transformation Model was developed to reflect evidence-based best practices that have emerged from Intel's collaborations with school systems and governments in more than 100 countries to address the practical approaches to deep, large-scale, systemic change with ICT, to create sustainable improvements in student learning. 
Intel's model of education transformation provides a holistic framework that encompasses the seven essential elements shown in Fig. 1 and facilitates second order change for K-12 educational technology initiatives as a systemic approach that supports best practices for achieving reform.

Intel has combined advocacy for policy reform, leadership, curriculum standards and assessment, sustained professional development efforts, information and communications technology, support of research and evaluation, and sustainable resourcing to help countries create an effective approach to 21st century education.

While each education transformation initiative has a unique starting point and vision of success, transformed environments share many common characteristics (Intel Corporation 2014b). In the current era of Intel education initiatives aimed at developing solutions, hardware, software and tools for learning, these same elements are necessary to enable smart learning environments.

ICT

ICT provides the foundation for the systemic transformation of a smart learning environment. ICT delivers the tools needed to enhance teaching and learning and support student-centered learning environments. As noted by Jim Collins, in his book Good to Great, technology is an accelerator. If technology is implemented well, with the right vision and plan, better results may be obtained much more quickly. However, poorly implement technology, with no vision, will result will be the opposite (Collins 2001).

Smart learning environments utilize education technologies to provide essential tools for educators to personalize learning, adapt teaching \& assessment, and create authentic learning environments for students. Effective eLearning environments combine student and teacher devices with high-quality education software, broadband Internet access, robust infrastructure, and secure cloud services to bring resources into the classroom and enable personalized learning experiences.

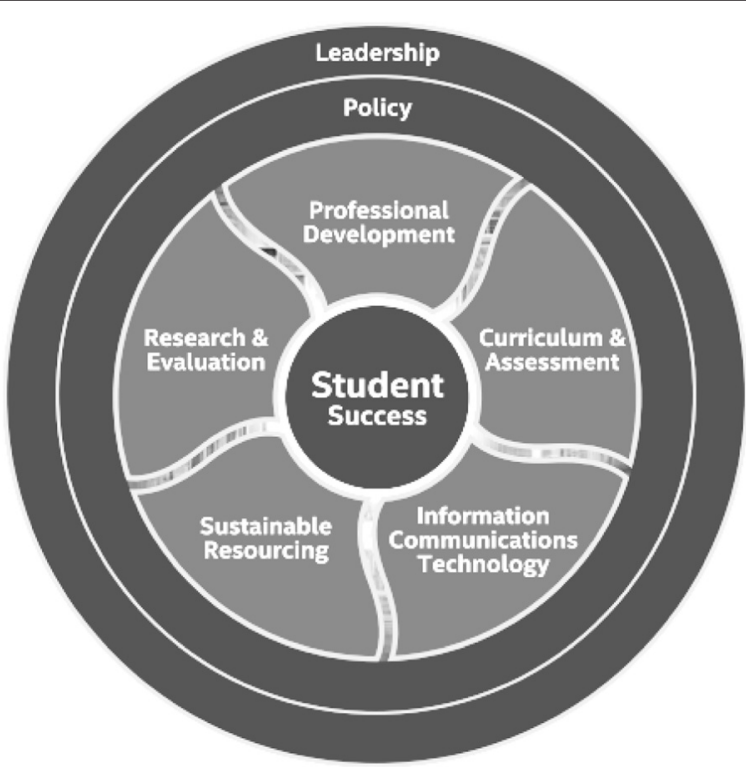

Fig. 1 The education transformation model 
An analysis of research conducted by Intel Corporation on education technology environments in 13 countries integrating ICT into specific classrooms found that teachers, whose students have lab and classroom access to ICT, or have a 1:1 environment, were both significantly more likely to use ICT than their peers who only have access to a computer lab. In most classes that were observed, students displayed basic use of ICT in their schools such as conducting Internet searches, performing routine skills or completing exams. However, innovative uses of ICT in the classrooms with access afforded new learning opportunities previously unavailable such as analyzing data or information, accessing information not available in print, and using ICT to collaborate with other students to construct project based learning activities. This finding suggests that having some flexibility in where students can access the Internet enables teachers to use more ICT with their students (Light and Pierson 2011).

Further research sponsored by Intel, into effective integration of technology into classroom instruction was conducted in Argentina and Russia. These studies used an instrumental case study approach designed to observe the classroom experience of students and teachers in schools where students are using laptops daily and to document the types of practices emerging around these tools. To further understand how access to educational tools and resources in the classroom influences the possibilities for creating engaging and supportive learning environments for students, case studies in five schools were conducted.

This exploratory research clarified to the researchers how providing good educational resources is a concern for schools in all countries, but the level of challenge this presents is a fundamental aspect of schools in developing countries. Schools studied, frequently lack many educational tools and resources that schools in wealthier countries take for granted. The lack of resources in the classroom manifests in many ways, such as a lack of reference materials for students, no textbooks at all or only a few copies which students share, no writing paper for students, no paper or no ink for the printer, or no chalk-and the list can go on. The lack of such resources may mean that teachers cannot assign students important learning activities, such as doing independent research or writing a long essay or story; neither can they print out student work to take home.

Each of the schools studied provide illustration of how the ICT resources had become a daily part of learning in the classroom through a mix of pre-existing teaching and learning strategies modified and enriched by the technology. In these classrooms, the Intel Classmate PCs, embedded in an eco-system of interactive whiteboards, a virtual learning platform, and wireless connectivity were being used frequently. In Argentina, students use the devices as often as the combination textbook, workbook, study guide, and notebook, or "copybooks". In Russia, the laptops, combined with virtual learning environments, allowed the schools to integrate easy, computer-supported assessment and self-reflection into their lessons. Overall, effective ICT integration was essential for these new learning strategies, shifting the pedagogical paradigm was the following challenge;

- Successful schools have common beliefs about learning and student-teacher relationships,

- The greatest difference was in embodied practice, by creating a more personalized learning environment. 
- The differences are shaped by infrastructure, existing pedagogical models, policy constraints (curricula, testing, administration), and leadership.

Key changes in teacher attitudes, knowledge and behaviors were identified, consisting of: a shift in beliefs about how students learn, a deeper understanding of new teaching strategies, changes in student learning activities and changes in how ICT was used to promote learning, including an increase in classroom management and access to educational resources that resulted in more student time on task (Light and Pierson 2012a); (Light and Pierson 2012b).

In addition, to individual technologies for students and teachers, this same Intel funded research shows understanding the broader, systemic impact of ICT can improve educational results through scalable, sustainable infrastructure that provides critical back-end capabilities to support teaching and learning. Such infrastructure may include a secure private cloud for resources available within the school system, as well as local infrastructure linked to resources available through public cloud services that provide:

- Low cost, low maintenance classroom networks that can host secure digital content and learning management systems

- Secure networks that extend access beyond the school building, improves communication between school and home, and facilitates school-community connections

- Increased student collaboration that allows students to work together at school or from home and allows them to communicate freely

- Advanced assessment and analytics tools that help teachers integrate self-reflection into lessons, and help school leaders identify and improve evidence-based strategies.

\section{Curriculum \& assessment}

Tomorrow's citizens and workers deserve an education that prepares them-and their nation's economy - to thrive in a world of rapid change and widespread globalization. Smart learning technologies enable students to conduct independent research, think critically \& solve problems, communicate \& collaborate, and understand societal issues related to digital citizenship. Although the integration of technology into the curriculum has been underway for many years, due to constrained resources technology access has often been limited to computer labs or mobile carts, affecting a teachers' ability to incorporate technology into the curriculum. As a result, use of technology rarely enhanced teaching and learning and instead was limited to computer literacy instruction. Today, with improved access and an increase in one-to-one and mobile technologies, Laptops, tablets and portable devices are increasingly serving as personal teaching and learning tools that are used throughout the day for many educational tasks and subjects. In addition, digital content is more available and accessible.

To transform schools into education systems of smart learning environments, technology enabled curriculum and instruction should include: engaging content, personalization of learning activities, and alignment to formative assessment strategies. Technology provides unprecedented opportunities for more student-centered and personalized learning. By providing access within the school to resources, events and information from outside the school, educators can take advantage of the 
student's interests to engaged and invested in their learning. As a result, when these educational resources are combined with the digital tools that enable timely and relevant data collection, better understanding and informed instructional decision making takes place (Grant and Basye 2014).

Technology enables new learning experiences when combined with the traditional school experience. In addition, technology enables new "blended learning" strategies for a student to learn partially through a formal education environment away from home and at least in part through online delivery with some element of student control over time, place, path, and/or pace. Blended learning provides a personalized experience that allows each student to work at his or her own pace, supplementing the school curriculum. By leveraging technology, blended learning programs can let students use preferred learning modalities, and receive frequent and timely feedback on their performance for a far higher quality learning experience. In addition to the more personalized, learner-centric academic pathway, students and parents express interest in online and blended learning environments due to the opportunity to offer expanded course options and address scheduling concerns. In a US focused study from Project Tomorrow, Engaging Students, Empowering Learning: New Roles for Digital Content and Games in the Classroom, when asked about why they would like to take an online class, almost half of all middle school students surveyed, indicated a desire to be in control of their own learning, to get extra help in a challenging subject, and to work at their own pace. In addition, $38 \%$ of teachers reported that the use of digital content helps student develop critical thinking and problem solving skills, up from $27 \%$ in 2009 (Project Tomorrow 2014). However, the report also states that $60 \%$ of school principals responding to the annual Speak Up survey indicated that not having enough computers or devices with Internet access is a major obstacle to the greater adoption of digital content in their schools.

To ensure that students gain critical skills and knowledge to succeed, strong curriculum should be combined with standards and accurate assessments. The result is more effective measures of students' knowledge, skills, and progress across various subjects. Formative assessments that align with curriculum changes, enable teachers improve instruction in real time. With digital content providing access to more student data, formative assessment of their understanding during instruction provides both the student and the teacher feedback that can be used to quickly assess learning, adapt content, personalize instruction, and improve outcomes. Formative assessments can empower students, shifting from passive to active learners who understand their strengths and weaknesses, recognize gaps in their learning, and develop a plan for addressing them (Intel Corporation 2014).

The result of these pedagogical strategies is the creation of authentic learning opportunities for students. The goal of a smart learning environment is to utilize technology to bring real life experiences into the classroom to engage students, and prepare them for further education, careers, and citizenship in a way that traditional practices often fails to do.

\section{Professional development}

Following advances that allow ICT to be more available and mobile, and policies that include uses of ICT in the classroom, technology enabled learning is beginning to reshape the activities in many classrooms. However, for sustained transformation, much more than the technology must be considered. Intel officers and Sr. Management 
regularly remark that, "Computers aren't magic, teachers are." This comment stems from the awareness that although ICT in education may enable change at an accelerated rate, transforming the activities within the classroom depends on the teacher's knowledge, attitudes and behaviors. In fact, many believe primary challenges are more in the area of institutional capacity and teacher professional development, rather than in technical areas (Lopes 2003).

As recent demands on the teaching profession have increased, much of these challenges due to increased accountability requirements, student assessment and monitoring requirements have increasingly confronted school leadership. The accountability of teachers has received much attention from policymakers in the form of student performance. While research indicates that factors such as working conditions, including class size, administrator support, peer support, and student discipline, are associated with teacher preparation (Johnson et al. 2004), the use of test scores is a controversial basis for teacher performance management.

Over the past two decades Intel has spent a great deal of time, effort, and money studying effective teaching and learning, and has chosen the approach that one of the best investments a government can make to improve student learning is to invest in teacher professional development. Access to technology without systemic supports such as policy, curriculum alignment, assessment and leadership that does not have a strong teacher professional development and support strategy will only lead to disappointing results. As a result, any effort possible to support teacher's knowledge, attitudes and behaviors in shaping classroom instruction and collaboration are critical.

One example of the importance of teacher professional development is the SITESM2 study of innovative pedagogical uses of technology. This study examined 174 schools in North and South America, Africa, Europe, Asia, and Australia. This study identified "Essential" and "Contributing" conditions underlying sustainable innovative pedagogical practices of technology use. Essential conditions, as identified by the research, were those conditions that were necessary for sustained innovation but were insufficient to act alone. Essential conditions for sustainability require support from three main actors: teachers, principals, and students. Additional contributing conditions were those found to facilitate the innovative practices, such as: Innovative Champions, Supportive Plans and Policies, and adequate Funding, (Kozma 2003). Most notably, the primary condition for sustaining an innovation is teacher support. Without teacher support, the innovation simply cannot occur.

Such innovative pedagogical approaches are critical to engage higher order thinking skills and intellectual capacity of the student needed to face today's global economy and economic competiveness. Researchers such as Hanushek \& Woessmann \& The OECD have established a link between engagement of K12 students in higher order thinking and complex problem solving with higher economic viability, (Hanushek and Woessmann 2010); (OECD 2010a). Appropriate professional development provides the teachers with the understanding and the relevance of the proposed change, and initiates the shift in a teacher's knowledge, attitudes and classroom behaviors that leads to new teaching and learning strategies for students.

Educators, like students, thrive when given the proper tools, training, and inspiration. Professional development resources that make the most of modern, personalized learning environments and technology tools enable effective use of today's technologies. 


\section{Leadership}

School leadership occurs across multiple levels. The first level, the highest, is the Macro level at the national or provincial ministry of education that sets overall policy, curricula, and national assessment standards. Next, at the mid- or Meso level, consists of school level leadership involved in the day-to-day decision making. Finally, the Micro or implementation level where leadership is viewed in the classroom, (Price and Roth 2010). While issues of national leadership are important for technology projects, (Kozma 2005) for the purpose of this paper, our focus is on leadership within the schools.

Principal support is crucial. According to the report of the second information technology in education study, (SITES M2), principles act as facilitators or gatekeepers of innovative technology \& pedagogical practices (Kozma 2003). The principal's support as illustrated in the research shows that not only is the leadership support of teachers essential, but also support of the innovation itself. As a result of the teacher interviews and classroom observations of the Intel education programs, the support required from school leadership becomes evident. Project based learning strategies, enabled by technology, and built around student centered and personalized learning, challenges traditional classroom teaching methods. Early in the Intel research, school leaders were observed questioning a classroom environment that includes students out of their seats, interacting in groups with teachers moving about the classroom interacting with groups of students. This collaborative, project based environment is drastically different from students sitting in orderly rows with the teacher at the head of the class lecturing. To school leaders unfamiliar with new dynamic classroom environments, project based instruction could appear as "chaos" resulting in the Principal interfering to return "order" to the classroom, (Price et al. 2011b).

Following a series of classroom environment case studies to explore the contextual factors associated with effective use of ICT in the classroom, (Light et al. 2009) important factors associated with leadership support emerged. The findings from this study suggest three observations of the role of school level leaders in supporting a process of ICT integration and pedagogical innovation:

1. The leadership does not come only from the principal. In many schools, teacher leaders or other administrators were advocates for ICT focused teacher professional development and use of technology.

2. The leadership often begins with establishing a vision and providing clear expectations for teachers, but continues as support and guidance for teachers' technology use in the classroom. Evidence from the studies, suggest that most teachers had little prior experience with the activities they were being asked to do. In each of the schools observed, the principals, technology coordinators, and trainers were consistently inside the classrooms to provide support, suggestions, and encouragement.

3. The leadership consists of solving specific administrative and logistic challenges regarding ICT use. In each of the schools studied, time, infrastructure, staff, space, and funding were limited. In each case where strong leadership was exhibited, administrators found solutions to allow change and innovation to take place, with the resources that were available.

ICT infrastructure is a constant challenge, especially for schools in developing countries. The decisions administrators have to make are often frustrating because they cannot 
provide all students all the access that is desired. Moving forward in smart learning environments, the demands on leaders will only increase as traditional instruction is further challenged by online learning communities, personalized learning through gamification strategies and digital content and tools. Recognizing a framework of essential elements to consider for technology enabled learning will help with professional development strategies and allocation of resources.

\section{Policy}

Transformative policy is systemic, aligned, action-oriented, and sustainable. Reform efforts based on scalable policies that protect students, maintain data privacy, and advance teaching and learning with technology are critical. To achieve such transformative policies, "policymakers must be able to articulate a vision, develop a master plan, implement initiatives, and evaluate and adapt these initiatives relative to the vision." (Kozma 2011. p. 2).

Two transformative initiatives that have influenced education policy around the world in recent years have been: 1) the UN Millennium Development Goals and, 2) the OECD Programme for International Student Assessment (PISA). Each of which have had a considerable impact on how individual governments approach education policy issues and approaches.

Goal 2 of the Millennium Development Goals, is to: Achieve universal primary education. Target 2. A. states, "Ensure that, by 2015, children everywhere, boys and girls alike, will be able to complete a full course of primary schooling." (United Nations 2015. p. 24) As one of eight Millennium Development Goals, the initiative approached education policy as one of the anti-poverty strategies to generate new and innovative partnerships, and influence public opinion. (United Nations 2015) Although these are not policies targeted at technology, the role of technology in providing unprecedented access and opportunity is significant. The Millennium Development Goals Report 2015 states, "Today, 95 \% of the global population is covered by a cellular network, while mobile cellular subscriptions have grown to over 7 billion. Internet penetration has increased to $43 \%$ of the world's population, linking 3.2 billion people to a global network of content and applications." (p.12) Moving forward, technology is recognized as a way to collect data \& relay important information rapidly. As such, the post 2015 agenda includes, "adequate funding and renewed efforts to mobilize innovation, science and technology for sustainable development." (p. 68).

The OECD PISA is approaching the $6^{\text {th }}$ survey following a three year cycle that began in 1997. Designed to assess the competencies of 15 year-olds in reading, mathematics and science in 65 countries with an additional, optional assessment of creative problem solving and financial literacy, (OECD 2015). Initial exploration into education technology was included as a pilot on student performance in digital and print reading in the 2009 assessment. In the report, Inspired by Technology, Driven by Pedagogy: A Systemic Approach To Technology-Based School Innovations, (2010b) The OECD noted that although access to new digital technology has increased measurably in the past ten years, this technology, "has not been adopted as quickly and intensively as expected despite policy efforts to promote and support technology-based school innovations." (P. 11) The report presents strategies to implement and support technology-based monitoring and assessment innovation in schools. In 2015, the assessment will make greater use of computer-based assessments. 
These two initiatives illustrate how policy can identify roadblocks that slow progress or accelerate progress toward transformational use of educational technologies. Flexible policies at the national, state or province, and school levels should work together to encourage innovation and empower educators to use ICT in ways that advance learning and teaching (Intel Corporation 2014).

\section{Research \& evaluation}

Effective program evaluation is a systematic way to improve and account for education transformation strategies and interventions by clarifying procedures that are useful, feasible, ethical, and accurate. Applying a research and evaluation framework to guide educators in the effective integration of technology will help summarize and organize essential elements of a strategy.

To develop a smart learning environment, it is important to monitor, refine, and improve the components of the efforts continuously. Successful education reform should be based on future outlook, and should incorporate program data from the outset in regular evaluations and measurements. The success of an education transformation initiative can understood within two elements: 1) defining what success actual means in terms of specific objectives, and 2) the capture and analysis of metrics in order to provide both near-term and longer-term feedback on the achievement of the stated vision and objectives. These two elements help establish a feedback loop that helps remediate in the near-term, as well as drive continuous improvement in the long term.

Just as preliminary research provides systemic investigation that may inform strategy, focused evaluation provides understanding of the value or impact of an intervention. Identification of the activities that support a shift from traditional education systems to the desired innovative, project based, collaborative and personalized learning environment will require exploration beyond the classroom to include the wide-ranging systemic change of programs, practices, and policies based on the application of a clear theory of change. Essentially, monitoring performance to stated objectives provides evidence of change and indication in the success in achieving desired, or expected results.

Consideration of the importance that research and evaluation plays in developing a smart learning environment may not be immediately recognized, but evaluating any reform initiative and conducting specific research activities can help provide valuable information that identifies successes, areas of improvement, and unintended outcomes of an intervention.

\section{Sustainable resources}

Recognizing that a typical educational technology initiative may take years to develop, depending on its scope and scale, wise technology choices set a path for long-term sustainability. In order for the successful education transformation initiative to be sustained, it must deliver sustained value and drive toward continuous improvement in student performance. This means that the right decisions need to be made in the right stages of program development that lead in the direction of the ultimate vision.

Funding sources and models must also be considered for the long-term; and, Return on Investment (ROI) needs to factor-in total cost of ownership (TCO) against total value delivered from the program. While equipping students with mobile technologies can be accomplished fairly quickly, changes to teaching practice, curriculum, and 
assessment will unfold and deepen over a longer period. Even within a single school system, different schools and teachers will advance at varying rates, depending on matters such as effective leadership, support, and culture. The impact on student learning, equity, and other goals can take even longer to become apparent, and often continues to build over a more extensive period time.

Sustainable improvements in student outcomes require much more than a one-time infusion of technology. Teachers need ongoing time and resources for professional learning, curriculum modernization, lesson planning, and related tasks. The technology itself will require maintenance and replacement. Infrastructure must be monitored and expanded to keep pace with rising demands. What may start as a technology project must become a permanent part of the learning environment, supported by consistent, sustainable funding.

\section{Smart learning environments as disruptive patterns in education}

Looking forward, globalization and the social networks and interconnectedness among people, goods, and services, will continue to evolve. According to the Consortium for Research on Educational Access, since the year 2000, the trend has been for production of goods to follow the supply of workers, with China and India making rapid gains in Gross Domestic Product (GDP). The recent shifts in production to Indonesia, Brazil, and Bangladesh will create new educational challenges. In Bangladesh, for example, only $20 \%$ of those students entering 6th grade complete the 10th grade-largely because of the socio-economic status of the family. As employment and wages rise, retention at the secondary level is predicted to increase dramatically, (Ahmed et al. 2007).

Recent attention to STEM (Science, Technology, Engineering, Math) education emphasizes the influence workforce changes will continue to have on education. Employers indicate there is a growing need for applicants who have mastered 21st Century skills, most often referred to as the "4C's" (critical thinking, communication skills, collaboration, and creativity). In a survey of US executives, $75 \%$ responded that these skills will become more important, and stated that experienced workers were better at those skills than recent graduates, (American Management Association 2010).

Relatedly, as the knowledge economy grows, the need for data analytics and understanding expert systems increases. This domain of Computational Thinking refers to an analytical ability as a vital ingredient of science, technology, engineering, and mathematics (Mishra, et al. 2013). Lines are becoming blurred between formal, classroom instruction and informal, out of school exploration in emerging areas such as the Maker Movement. Makers are taking advantage of cheap, powerful, easy-to-use tools, plus easier access to knowledge, capital and markets to creating new physical objects that include smart electronics that can be connected through sensors operated through the powerful and emerging internet of things. A recent study by Intel Corporation into the Maker movement in the US, China \& Mexico found that the United States has the most established Maker community with many of the Makers surveyed responding that they have been involved in making activities since before the term was used to define the maker movement. China is the newest Maker market of the three included in the research, and there are signs that it may be the fastest growing. Mexico is the most collaborative of the Maker markets, and most interested in entrepreneurship (Intel Corporation: Meet the Makers study, Survey conducted in US, China, and Mexico by Harris Poll, Unpublished transcript). 
Globally, the Maker movement is experiencing rapid growth. According to Make magazine, starting in 2006 with the first single event, the number of events has risen to 100, and most recent attendance at the events has grown from 2011 to the end of 2013 Maker events across the globe rose by $335 \%$, with $64 \%$ more attendance in 2013 than in 2012, (Merlo 2014). In June of 2014 the White House hosted its first Maker faire during the event, President Obama said, "We're helping schools take shop class into the 21st century, because one of the things I'm really interested in is how do we redesign high schools so that young people are able to do stuff as they are learning", (United States, Whitehouse 2014).

To move beyond the rigid parameters of our current education systems, and incorporate the innovative and engaging approaches enabled by the technology and socially connections that continue to evolve, it is increasingly important that the interdependent components represented by the Intel education transformation model be addressed. Considering the challenges we have experienced in aligning such issues as ICT, professional development, curriculum and assessment, we can anticipate infinitely greater challenges as new, informal disruptions place even greater demands on our systems. It is increasingly important that we begin to consider these components and the influence they have on each other before we are expected to include additional informal, out of classroom instructional strategies.

\section{Conclusion}

Often, we hear that our education systems are broken. The issue is not so much that they are broken as it is that they were built at a time and for functions that are no longer critical, and measured in ways that are no longer meaningful. Today, we need far more people with analytical skills to pursue innovation in academia, in industry, in government. Today, our young people need a far better grasp of technology and science simply to live in this increasingly complex and rapidly changing world inundated with data, climate changes, and revolutionary advances in medical science. Today, we need systems of measurement and assessment that move away from an emphasis on subject knowledge, and move towards understanding skills and attitudes and the increasingly important competencies of critical thinking. As a result, as technology becomes ever more complicated, there is a better understanding of approaches to student learning through a process of constructing and developing knowledge and the meaning of learning, and smart learning environments reflect this.

A review of education technology research, based on over a decade of study, has shaped how the Intel Education solutions are developed, and illustrate how to transform teaching and learning. Working collaboratively, through public/private partnerships worldwide, the resources and solutions needed for effectively integrating technology into educational systems can be provided to promote problem solving, critical thinking and collaboration skills among students. Smart learning environments require a systemic reform process, in which stakeholders need to consider how policy changes in one area affect other areas. The consequences of making incomplete, poorly coordinated reforms could be tragic. One of the biggest challenges for ministries of education engaged in school reform is measuring whether they are having a real impact in the classroom. Viewing program evaluation and monitoring as external additive processes misses out on the opportunity for measures that focus on the effects of the 
teacher's direct actions and practice within a participatory classroom with the goal of improving the performance quality of the learners. Weaving technology into these reforms allows schools to monitor and measure academic performance where teaching and learning occurs.

Education reformers in the developed nations are paying increasing attention to the role technology plays in personalized, student-centered teaching practices, and this conversation has now begun in emerging market countries. Transforming the traditional classroom to an innovative, engaging smart learning environment requires ministries, education administrators, researchers, and teachers to broaden their view and deepen their conversation around the understanding of education technology and the impact of interdependent components.

\section{Competing interests}

The author declares that there are no competing interests.

Authors' information

Jon K. Price, Ph. D.

Research Scientist, Intel Education

In his current role, Jon is a Research Scientist for the Intel ${ }^{\circledR}$ Education Group, User Experience Team. Jon is responsible for managing the education technology research and evaluation efforts for Intel's global education initiatives.

His duties include design and grant management involving research and evaluation into how effective integration of technology into multiple levels of education can impact teaching, learning, education reform, and economic growth. Jon is a graduate of The University of New Mexico, the Harvard Graduate School of Education and received his PhD in Education from the Texas A\&M University College of Education.

Jon currently lives in Albuquerque, New Mexico, USA, with his wife and three children.

Received: 9 October 2015 Accepted: 12 November 2015

Published online: 18 December 2015

\section{References}

M. Ahmed et al., Access to Education in Bangladesh: Country Analytic Review of Primary and Secondary Education, 2007. Consortium for Research on Educational Access Transitions and Equity Retrieved from: http://www.create-rpc.org/pdf_ documents/Bangladesh_CAR.pdf

American Management Association, Critical Skills Survey, 2010. Retrieved from: http://www.p21.org/storage/documents/ Critical\%20Skills\%20Survey\%20Executive\%20Summary.pdf

F. Barrera-Osorio, L.L. Linden, The Use and Misuse of Computers in Education: Evidence from a Randomized Experiment in Colombia. World Bank Policy Research Working Paper Series, 2009. No. 4836Retrieved from: http://elibrary. worldbank.org/doi/book/10.1596/1813-9450-4836

J. Collins, Good To Great: Why Some Companies Make the Leap and Others Don't (Harper Collins, New York, 2001)

K. Douglas, Sharpening our focus in measuring classroom instruction. Educ. Res. 38(7), 518-521 (2009)

P. Grant, D. Basye, Personalized Learning: A Guide for Engaging Students With Technology (International Society for Technology in Education, Eugene, 2014)

M.H. Hannifan, D.W. Dalton, S. Hooper, Computers in education: ten myths and ten needs. Educ. Technol. 27(10), 8-14 (1987)

E.A. Hanushek, L. Woessmann, The High Cost of Low Educational Performance: The Long-Run Economic Impact of Improving PISA Outcomes. Commissioned by OECD, 2010. Retrieved from: http://www.oecd.org/pisa/44417824.pdf

Intel Corporation, Transforming Education for the Next Generation A Practical Guide to Learning and Teaching with Technology (Intel Corporation, Santa Clara, 2014b). Retrieved from: http://www.intel.com/content/www/us/en/ education/solutions/transforming-education-nextgeneration-guide.html

S.M. Johnson, S.M. Kardos, D. Kauffman, E. Liu, M.L. Donaldson, The support gap: new teachers' early experiences in high-income and low-income schools. Educ. Pol. Anal. Arch. 12, 61 (2004). Retrieved from: http://files.eric.ed.gov/ fulltext/EJ853526.pdf

R. Kozma (ed.), Technology, innovation, and educational change: a global perspective (International Society for Technology in Education, Eugene, 2003)

R. Kozma, National policies that connect ICT-based education reform to economic and social development. Hum. Technol. 1(2), 117-156 (2005)

R. Kozma, Policy for Educational Transformation: An Educational Policy Brief. Intel Corporation, 2011. Retrieved from: http://download.intel.com/education/transformation/EDUCATION_POLICY_22pg_Final.pdf

D. Light, E. Pierson, Increasing ICT use with students around the world: Intel ${ }^{\boxplus}$ Teach Essentials survey results from 13 participating countries. EDC/Center for Children and Technology, 2011. Retrieved from: http://download.intel.com/ education/EvidenceOflmpact/GlobalFollowUplntelTeachSurveyReport2011.pdf

D. Light, E. Pierson, Highlighting Changes in the Classrooms of a Successful 1 to 1 Program in Rural Argentina: Case Studies of Todos Los Chico's En La Red in San Luis. EDC/Center for Children and Technology, 2012a. Retrieved from: http://www.intel.com/content/www/us/en/education/evaluations/changes-in-argentina-schools.html 
D. Light, E. Pierson, Highlighting changes in Two Russian Schools with Successful One-To-One Laptop Programs: Moscow and Nizhny Novgorod Case Studies. EDC/Center for Children and Technology, 2012b. Retrieved from: http://www.intel. com/content/www/us/en/education/evaluations/changes-in-2-russian-schools.html

D. Light, S. Strother, D. Polin, Emerging changes in ICT-rich learning environments: The Intel ${ }^{\circledR}$ Teach Essentials Course and changing teacher practice in India, Turkey, and Chile (Center for Children and Technology Education Development Center Inc, New York, 2009)

M. Lopes, Incorporation of Information and Communication Technologies in Schools: The "Internet for Everyone" Project in Panama, 2003. Retrieved from: http://cyber.law.harvard.edu/sites/cyber.law.harvard.edu/files/ipt_analysis.pdf

V. Makrakis, Computer-resource teachers: a study and a derived strategy for their use in in-service training. Comput. Educ. 16(1), 43-49 (1991)

B. Means et al., Evaluation of Evidence-Based Practices in Online Learning: A Meta-Analysis and Review of Online Learning Studies (U.S. Department of Education, Washington, 2009). Retrieved from: http://www.ed.gov/rschstat/eval/tech/ evidence-based-practices/finalreport.pdf

S. Merlo, The Year of 100 Maker Faires, 2014. Makezine, January 1, 2014. Retrieved from: http://makezine.com/2014/01/ 01/the-year-of-100-maker-faires/

P. Mishra, J. Voogt, P. Fisser, C. Dede, EDUsummIT 2013 Thematic Working Group 6: Advancing computational thinking in the $21^{\text {st }}$ century, in Education, in Proceedings of Society for Information Technology \& Teacher Education International Conference 2014, ed. by M. Searson, M. Ochoa (AACE, Chesapeake, 2013), pp. 1016-1021. Retrieved from: http://www.curtin.edu.au/edusummit/local/docs/TWG6_Summary_Report.pdf

OECD, PISA 2009 Results: Executive Summary (Organisation for Economic Co-operation and Development, Paris, 2010a). Retrieved from: http://www.oecd.org/pisa/pisaproducts/46619703.pdf

OECD, Inspired by Technology, Driven by Pedagogy: A Systemic Approach to Technology-Based School Innovations. OECD publishing (Organisation for Economic Co-operation and Development, Paris, 2010b). Retrieved from: http://www.oecd.org/edu/ceri/inspiredbytechnologydrivenbypedagogyasystemicapproachtotechnologybasedschoolinnovations.htm

OECD, PISA 2012 Results (Organization for Economic Co-operation and Development, Paris, 2015). Retrieved from: http://www.oecd.org/pisa/keyfindings/pisa-2012-results.htm

J. Price, M. Roth, Evaluating Effective Teaching and Learning within Complex Levels of Interaction, in Proceedings of the Global Learn Asia Pacific 2010, 2010

J. Price, D. Light, V. Michalchik, Ten Years of Evaluation within Intel Education Initiatives (Intel Corporation, Santa Clara, 2011a). Retrieved from: https://www-ssl.intel.com/content/www/us/en/education/evaluations/ten-years-of-evaluation-withinintel-education-initiatives.html

J. Price, M. Roth, D. Arati, The Critical Role of School Leadership: Strategies For Successful Technology Implementation, in Proceedings of the 3rd International Conference on Education and New Learning Technologies. Barcelona, Spain, July, 2011b, p. 2011

Project Tomorrow, Digital Teachers, Digital Principals: Transforming the Ways We Engage Students. Speak Up Survey Results, 2014. Retrieved from: http://www.tomorrow.org/speakup/downloads/PROJECT-TOMORROW-10-3-14.pdf

F. Scheuermann, K. Kikis, E. Villalba, A Framework for Understanding and Evaluating the Impact of Information and Communication Technologies in Education, 2009. Retrieved from: http://www.rcc.gov.pt/SiteCollectionDocuments/ EfectsICTinEducation-OCDE2009.pdf

M. Trucano, Worst Practice in ICT use in Education. Blogpost. World Bank, 2010. Retrieved from: http://blogs.worldbank. org/edutech/worst-practice

United Nations, The Millennium Development Goals Report 2015 (United Nations, New York, 2015). Retrieved from: http://www.un.org/millenniumgoals/2015_MDG_Report/pdf/MDG\%202015\%20rev\%20(July\%201).pdf

United States, Whitehouse, The White House Hosts Its First-Ever Maker Faire, 2014. June 18, 2014. Retrieved from: http://www.whitehouse.gov/photos-and-video/video/2014/06/18/white-house-hosts-its-first-ever-maker-faire\#transcript

P. West, Teachers' Computer Skills Self-Taught, Not a Result of Training, Survey Finds, 1990. Education Week Online: http://www.edweek.org/ew/articles/1990/05/09/09390010.h09.htm

\section{Submit your manuscript to a SpringerOpen ${ }^{\circ}$ journal and benefit from:}

- Convenient online submission

- Rigorous peer review

- Immediate publication on acceptance

- Open access: articles freely available online

- High visibility within the field

- Retaining the copyright to your article

Submit your next manuscript at $>$ springeropen.com 